\title{
Piezo-thermal Probe Array for High Throughput Applications
}

\author{
Angelo Gaitas ${ }^{1,2, a)}$ and Paddy French ${ }^{2}$ \\ ${ }^{1}$ PicoCal, Inc., 333 Parkland Plaza, Ann Arbor, MI48103 ²EI-EWI, Delft University of Technology, \\ Mekelweg 4, 2628CD, Delft, The Netherlands
}

\begin{abstract}
Microcantilevers are used in a number of applications including atomic-force microscopy (AFM). In this work, deflection-sensing elements along with heating elements are integrated onto micromachined cantilever arrays to increase sensitivity, and reduce complexity and cost. An array of probes with 5-10 nm gold ultrathin film sensors on silicon substrates for high throughput scanning probe microscopy is developed. The deflection sensitivity is $0.2 \mathrm{ppm} / \mathrm{nm}$. Plots of the change in resistance of the sensing element with displacement are used to calibrate the probes and determine probe contact with the substrate. Topographical scans demonstrate high throughput and nanometer resolution. The heating elements are calibrated and the thermal coefficient of resistance (TCR) is $655 \mathrm{ppm} / \mathrm{K}$. The melting temperature of a material is measured by locally heating the material with the heating element of the cantilever while monitoring the bending with the deflection sensing element. The melting point value measured with this method is in close agreement with the reported value in literature.
\end{abstract}

\section{Keywords}

Microcantilevers; Scanning probe microscopy; Piezoresistive sensing; Parallel imaging; Elastography; Mechanical characterization; Melting point; High throughput

\section{Introduction}

\begin{abstract}
Microcantilevers are used in a number of applications including atomic-force microscopy (AFM) [1]. Deflection-sensing elements are integrated onto micromachined cantilevers to increase sensitivity, and reduce complexity and cost. These sensing elements are made by selectively doping silicon [2,3], or by depositing metal or metal oxide films on cantilevers such as gold $[4,5]$. Compared with doped-silicon sensing elements, deposited metal film elements have certain advantages including simplified fabrication, a lower manufacturing cost, and the capability to scale down to smaller dimensions while maintaining sensitivities and exhibiting lower noise. Metallic sensing elements enable the use of alternative substrate materials (such as polymers), that tend to exhibit higher compliance properties and improved thermal isolation. We have already used polymer cantilevers for explosive detection [6], patch clamping [7], scanning thermal microscopy [8,9], and elastography measurements [7, 9]. Thin metal film sensing elements with thickness less than $10 \mathrm{~nm}$ have increased
\end{abstract}

\footnotetext{
(C) 2012 Elsevier B.V. All rights reserved.

a)Tel.: 734-913-2608. Fax: (734) 619-6676. angelo@ picocal.com. Address: 333 Parkland Plaza, Ann Arbor, MI 48103, USA.
}

Publisher's Disclaimer: This is a PDF file of an unedited manuscript that has been accepted for publication. As a service to our customers we are providing this early version of the manuscript. The manuscript will undergo copyediting, typesetting, and review of the resulting proof before it is published in its final citable form. Please note that during the production process errors may be discovered which could affect the content, and all legal disclaimers that apply to the journal pertain. 
piezoresistive sensitivity [10]. Microcantilevers with metal film elements have been used as microheaters [11] and for scanning thermal microscopy [12]. Ultrathin metal films exhibit higher TCR [13].

Using metal sensors is relatively simple to expand to a one or two dimensional probe array for higher throughput multi-location measurements overcoming AFMs throughput limitations. Higher throughput is very important in many applications ranging from semiconductor failure analysis and production applications (where entire wafers or large areas need to be examined in relatively short time), to biological applications such as cell elastography [14] and high throughput patch clamping. Nanofabrication and nanotechnology applications that would benefit from a higher throughput multi-probe system include nanoscale imaging, thermo-chemical patterning [15], and nano-CVD [16], nano-indentation, nano-patterning, and dip pen nanolithography [17]. Finally, material characterization techniques that rely on AFM would benefit from faster analysis rates, simultaneous multiple location measurements, and lower costs, some examples include thermo-mechanical and mechanical analysis.

The probe arrays described in this paper include a monolithic integration on each cantilever of a heating element (which can also be used for temperature sensing) and a deflection (or displacement) sensing element. Gold films of $5 \mathrm{~nm}$ to $10 \mathrm{~nm}$ thicknesses were deposited on a silicon cantilever to form both sensing elements. The probes operate without the need of an optical lever required by AFM systems to detect cantilever deflection. In addition, the probes have a very large dynamic range of tens of micron. This paper is an expansion of prior work on single cantilevers with monolithically integrated displacement sensors and micro heaters/thermal sensors for melting point measurements and thermo-mechanical analysis [11], material characterization of mechanical properties [18], and scanning probe microscopy [18].

\section{Device and fabrication}

The device is fabricated in a process described in Fig. 1 and is similar to the ones reported previously $[11,18]$. A thermal oxide masking layer is grown and patterned for the probe tip on a silicon-on-insulator (SOI) wafer. The tip is formed using $\mathrm{KOH}$ anisotropic etching (Fig. $1(1)$ ), the oxide mask is then removed, and the tip is sharpened with several oxide sharpening steps [19]. The oxide sharpening step involves thermal oxidation followed by hydrogen fluoride (HF) etching repeated at least three times. A $100 \mathrm{~nm}$-thick silicon oxide is thermally grown on the wafer to provide electrical insulation (Fig. 1(2)). The cantilever is patterned on the front side of the wafer with the Bosch deep reactive-ion etching (DRIE) process (Fig. 1(3)). Metal lines are evaporated and patterned on top of the cantilever structure with lift-off process to form the sensing elements (Fig. 1(4)). The thicknesses of the metal layers are measured during the evaporation and the variation is within $\pm 10 \%$. The suspended cantilever is then formed by back side DRIE with an etch rate of $3 \mu \mathrm{m} / \mathrm{min}$ (Fig. 1(5)). The $1 \mu \mathrm{m}$ buried oxide layer of the SOI wafer acts as an etch stop to prevent the back side DRIE from attacking the Si cantilever structures. Finally, the probes are released by removing the buried oxide layer using buffered HF etchant. If the probe array is used with an AFM, then a thin layer of aluminum is evaporated on the back-side to improve the laser reflection (Fig. 1(6)).

Figure 2 shows the resulting micro-cantilever array. The design includes two sensing elements on one cantilever, each of which consists of a gold film deposited on a silicon oxide/silicon cantilever. The resistor covering the tip area forms a micro-bolometer (heating element) and a resistor near the base of the cantilever forms a deflection sensing element. 
The rectangular cantilever is $100 \mu \mathrm{m}$ wide, $200 \mu \mathrm{m}$ long, and $2 \mu \mathrm{m}$ thick. The resulting cone shaped tip has a $100 \mathrm{~nm}$ diameter and a $7.5 \mu \mathrm{m}$ height.

\section{Experimental set-up}

The experimental set-up is shown in Fig. 3. The change in resistance of the deflection sensing element of the cantilever is directly measured using a micro-Ohm meter (Agilent, HP-34420A), without the need of an interface amplifying circuit. The thermal element is heated using a variable power supply (Keithley 2400). The data are acquired with a LabView program. A piezoelectric XYZ stage with $100 \mu \mathrm{m}$ range and nanometer resolution on each axis (PiezoJena, Tritor 100) is used to move the sample underneath the probe array. A Zaber motorized stage is used for larger movements is the XYZ direction.

\section{Deflection sensing element characterization and probe-sample contact}

The resistances of the active elements used for these measurements vary between $409 \Omega$ and $433 \Omega$. The noise spectrum of the sensors was measured as described in previous work [18]. $1 / \mathrm{f}$ noise was not observed from $10 \mathrm{~Hz}$ to $1 \mathrm{KHz}$, while the white noise floor was $22 \mathrm{nV} /$ $\sqrt{\mathrm{Hz}}$, which resulted in minimum detectable deflection of $0.7 \mathrm{~nm}[18]$.

Typically, the probe array is positioned near the sample area. The sample used for these tests is a glass slide. The sample is gradually brought closer to the array, while the probes are optically and electrically monitored to determine contact. Figure 4 shows a method to determine contact by monitoring the probes optically through a high resolution microscope. As soon as the probes come in contact with the sample their reflection changes. Optical monitoring can determine contact with better than $0.5 \mu \mathrm{m}$ accuracy.

Alternatively, each cantilever can be monitored electrically by measuring the change in the resistance of the deflection sensing element similarly to the "force-curves" generated using AFM systems. These "force-curves" can be used to determine probe-sample contact and to calibrate the probes. In Fig. 5 the arrows indicate the direction of the movement. The thin (blue) line represents the trace (probe and sample moving toward each other) and the thick (red) dashed line represents the re-trace (probe and sample moving away from each other). The vertical axis is the change of the resistance of the resistor measured with a micro-ohm meter (Agilent, HP-34420A) and the horizontal axis is the Z-axis movement toward and away from the sample measured with the piezoelectric stage. From the curves, the deflection sensitivity of the probes $((\Delta \mathrm{R} / \mathrm{R}) /$ deflection $)$ is calculated to be $0.2 \mathrm{ppm} / \mathrm{nm}$. From $[18,20]$ and the experimental data, the average gauge factor is calculated to be $3.16 \pm 0.05$. Probes in the same array exhibit high consistency in the measured sensitivity and measurement repeatability. There is less than $2 \%$ variation in the value of the gauge factor in cantilevers of the same array.

\section{Topographical scanning}

Figure $6 \mathrm{~b}$ show a $10 \mu \mathrm{m}$ line scan over the top surface of a $10 \mu \mathrm{m}$ pitch square grating with 1 $\mu \mathrm{m}$ height (fig. 6a). The line scan in Fig. $\mathrm{b}$ is a plot of the change in deflection in $\mu \mathrm{m}$, after converting the resistance data using the deflection sensitivity calculated above, vs. the inplane (XY plane) movement. In figure $6 \mathrm{~b}$ the probe moved in $0.2 \mu \mathrm{m}$ steps in the $\mathrm{X}$ direction.

Eliminating the need for an optical lever is particularly useful when an array of probes is used to increase throughput. In Fig. 7 unprocessed data of $40 \mu \mathrm{m} \times 40 \mu \mathrm{m}$ area scans acquired by 3 different cantilever probes scanned over the $10 \mu \mathrm{m}$ pitch square grating (Fig. 6a) are shown. The probes moved in $1 \mu \mathrm{m}$ steps in the $\mathrm{X}$ direction and $1 \mu \mathrm{m}$ steps in the $\mathrm{Y}$ 
direction. Indicative line scans for each probe are shown. The scanning speed was $5 \mu \mathrm{m} / \mathrm{s}$. The data were acquired with multimeter.

\section{Thermo-mechanical applications}

The heater is independently calibrated using a $12 \mu \mathrm{m}$ size thermocouple (Omega, CHAL-0005) that is brought into contact with the heating element as shown in 8a (described in detail in [11]). A variable power supply (Keithley 2400) is used to increase the power through the heating element while monitoring the temperature with the thermocouple. Figure $8 \mathrm{~b}$ shows the near linear relationship of the power through the heating element with temperature. Fig. $8 \mathrm{~b}$ is used to derive the temperature from a known value of power through the heating element. From this measurement the TCR of the heater was calculated to be approximately $655 \mathrm{ppm} / \mathrm{K}$.

The melting temperature of naphthalene C10H8 (Sigma-Aldrich, Inc., 01422-250MG, Melting Point Standard) with a melting point between $79-81{ }^{\circ} \mathrm{C}\left( \pm 0.3{ }^{\circ} \mathrm{C}\right)$ is measured with the piezo-thermal probe in a similar way to [11]. A variable power supply is used to increase the power through the heating element of each probe, while the change in resistance of the deflection sensing element of each probe is directly measured using a micro-ohm meter. The calibration curve of Fig. $8 \mathrm{~b}$ is used to convert power to the corresponding temperature. Fig. 9 shows the first order derivative $(\Delta \mathrm{R} / \Delta \mathrm{T})$ of the deflection sensing element on the vertical axis with temperature increase of the heating element on the horizontal axis. Near the reported melting temperature a local decrease in resistance is observed at $79.7^{\circ} \mathrm{C}$. The local decrease in resistance is interpreted as a movement of the probe toward the sample, an indent toward the sample, caused from the melting.

\section{Conclusions}

In conclusion, an array of probes with $5 \mathrm{~nm}-10 \mathrm{~nm}$ gold ultrathin film sensors on silicon substrates for high throughput scanning probe microscopy has been successfully fabricated continuing our previous work. The deflection sensitivity is $0.2 \mathrm{ppm} / \mathrm{nm}$. Plots of the change in resistance with displacement are used to calibrate the probes' deflection element, while plots of change in power and resistance with temperature are used to calibrate the heating element. Topographical scans demonstrate high throughput and nanometer resolution. Melting point measurements demonstrate the ability to conduct high throughput material characterization measuring two parameters of each individual cantilever in an array simultaneously, namely temperature and deflection.

Sensitivity and compliance can be further improved with the use of polymer, instead of silicon, as a structural material for the cantilevers. Sensitivity and gauge factors can be further improved using alternative sensing elements instead of gold such as thin films of other metals and metal oxides. These innovations would allow for a wealth of new nanoscale high throughput applications including integrated circuit hot spot detection, material characterization, nano-indentation, dip pen nanolithography, cellular imaging, multiple single cell elastography and patch clamping.

\section{Acknowledgments}

The authors thank Dr. Weibin Zhu for help with device fabrication and Dr. Tao Li for consulting. We thank Prof. Yogesh Gianchandani, Dr. Cheryl Albus, and Dr. James Deatherage for their advice and support. This work was supported by the National Science Foundation (NSF Award No. 0822810) and the National Institutes of Health (R43GM084520). 


\section{References}

1. Albrecht TR, Akamine S, Carver TE, Quate CF. Microfabrication of cantilever styli for the atomic force microscope. Journal of Vacuum Science \& Technology A: Vacuum, Surfaces, and Films. 1990; 8(4):3386-3396.

2. Chui BW, Mamin HJ, Terris BD, Stowe TD, Rugar D, Kenny TW. Low? stiffness silicon cantilevers for thermal writing and piezoresistive readback with the atomic force microscope. Appl Phys Lett. 1996; 69:2767.

3. Polesel-Maris J, Aeschimann L, Meister A, Ischer R, Bernard E, Akiyama T, Giazzon M, Niedermann P, Staufer U, Pugin R, de Rooij NF, Vettiger P, Heinzelmann H. Piezoresistive cantilever array for life sciences applications. J Phys: Conf Ser. 2007; 61:955-959.

4. Li M, Tang HX, Roukes ML. Ultra-sensitive NEMS-based cantilevers for sensing, scanned probe and very high-frequency applications. Nature Nanotechnology. 2007; 2:114-120.

5. Calleja M, Rasmussen PA, Johansson A, Boisen A. Polymeric mechanical sensors with piezoresistive readout integrated in a microfluidic system. Proc SPIE. 2003; 5116:314.

6. Zhu, Weibin; Park, Jung Su; Sessler, Jonathan L.; Gaitas, Angelo. A colorimetric receptor combined with a microcantilever sensor for explosive vapor detection. APPLIED PHYSICS LETTERS. 2011; 98:123501.

7. Lai, King; Gaitas, Angelo; Xi, Ning; Yang, Ruiguo; Fung, Carmen. Development and Testing of Nano Robot End Effector for Cell Electrophysiology and Elastography Studies. Proceedings of the IEEE NANO 2011 Conference; 2011.

8. Li, Mo-Huang; Yogesh, B. Gianchandani, Microcalorimetry applications of a surface micromachined bolometer-type thermal probe. J Vac Sci Technol B. 2000; 18:3600.

9. Lai, King; Gaitas, A.; Yang, Ruiguo; Fung, Carmen; Xi, Ning. Ultra-compliant thermal AFM probes for studying of cellular properties. 10th IEEE Nanotechnology Conference (IEEE-NANO); 2010.

10. Li C, Hesketh P, Maclay G. Thin gold film strain gauges. J Vac Sci Technology. A12(3):813. 1994, 813-819.

11. Gaitas, Angelo; Gianchandani, Sachi; Zhu, Weibin. A Piezo-Thermal Probe for Thermomechanical Analysis. Rev Sci Instrum. 2011; 82:053701. [PubMed: 21639501]

12. Li M-H, Gianchandani YB. Microcalorimetry Applications of a Surface Micromachined Bolometer-type Thermal Probe. Journal of Vacuum Science and Technology B: Microelectronics and Nanostructures. 2000; 18(6):3600-3.

13. Gaitas A, Zhu W, Gulari N, Covington E, Kurdak C. Characterization of room temperature metal microbolometers near the metal-insulator transition regime for scanning thermal microscopy. Appl Phys Lett. 2009; 95:153108.

14. Favre, Mélanie; Polesel-Maris, Jérôme; Overstolz, Thomas; Niedermann, Philippe; Dasen, Stephan; Gruener, Gabriel; Ischer, Réal; Vettiger, Peter; Liley, Martha; Heinzelmann, Harry; Meister, André. Parallel AFM imaging and force spectroscopy using two-dimensional probe arrays for applications in cell biology. Journal of Molecular Recognition, Special Issue: AFM on Life Sciences and Medicine. 2011; 24(3):446-452.

15. Basu A, McNamara S, Gianchandani YB. Scanning Thermal Lithography: Maskless, Submicron Thermochemical Patterning of Photoresist by Ultracompliant Probes. Journal of Vacuum Science and Technology B: Microelectronics and Nanostructures. 2004; 22(6):3217-3220.

16. Gaitas, Angelo; Mitra, Bhaskar; Basu, Amar; Zhu, Weibin. Scanning Probe Assisted localized CNT growth, Patent application number 12/464,039, Publication number US. 2010/0055349 A1. 2009.

17. Zhang, Ming; Bullen, David; Chung, Sung-Wook; Hong, Seunghun; Ryu, Kee S.; Fan, Zhifang; Mirkin, Chad A.; Liu, Chang. MEMS nanoplotter with high-density parallel dip-pen nanolithography probe arrays. Nanotechnology. 2002; 13:212-217.

18. Gaitas, Angelo; Li, Tao; Zhu, Weibin. A Probe with Ultrathin Metal Piezoresistive Sensor for Scanning Probe Microscopy and Material Characterization. Sensors and Actuators A: Physical. 2011; 168(2):229-232.

19. Akamine, Barrett RC, Quate C. Improved atomic force microscope images using microcantilevers with sharp tips. Appl Phys Lett. 1990; 57:316. 
20. Sarid, D. Scanning Force Microscopy. Vol. I-XI. Oxford Univ. Press; New York: 1991. p. 253

\section{Biographies}

Angelo Gaitas is the CEO of PicoCal Inc. and he is also pursuing a Ph.D. in industry with Delft University of Technology. He received an M.B.A. from the University of Wisconsin at Madison, USA, in 2002, an M.S. in Solid-State Physics from the University of London, UK, in 1998, and a B.Sc. in Physics and Mathematics from the University of Wales-Swansea, UK, in 1997. His present research interests lie in microcantilevers for scanning probe microscopy, manufacturing, chemical, and biological applications.

Paddy French received his B.Sc. in Mathematics and M.Sc. in Electronics from Southampton University, UK, in 1981 and 1982, respectively. In 1986 he obtained his $\mathrm{Ph} . D$. ., also from Southampton University, which was a study of the piezoresistive effect in polysilicon. He then spent 18 months at Delft University, on the Royal Society European Exchange Programme, investigating new flip-flop sensor structures. In 1988 he moved to Japan and worked for 3 years in the Central Engineering Laboratories of Nissan Motor Company on sensors for automotive applications. He returned to Delft University to begin a three year FOM sponsored fellowship at the Laboratory for Electronic Instrumentation to study micromachining. Since 1994, he is one of the project leaders of this laboratory. His main research interests are silicon technology, mechanical sensors and actuators, MOSbased sensors and process optimization related to sensors. In 1999 he was awarded the Antoni van Leeuwenhoek chair. In 2002 he became head of the Electronic Instrumentation laboratory. 


\section{Highlights}

- Deflection-sensing elements and heating elements are integrated onto micromachined cantilever arrays.

- The sensing elements are made of $10 \mathrm{~nm}$ gold films on silicon substrates.

- Plots of the change in resistance of the deflection-sensing element with displacement are used to determine probe contact.

- Topographical scans demonstrate high throughput and nanometer resolution.

- The melting temperature of a material is measured using the integrated heating and deflection-sensing element. 


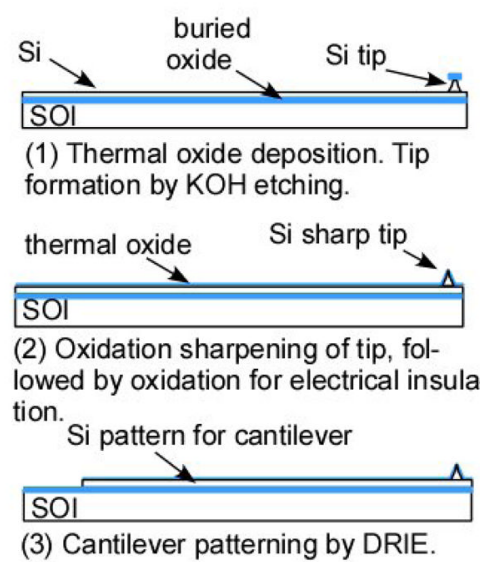

(3) Cantilever patterning by DRIE.

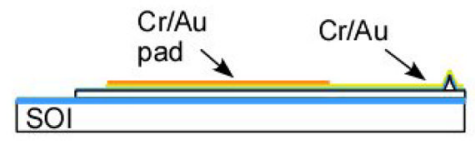

(4) Cr/Au deposition for heater/ piezoresistor. $\mathrm{Cr} / \mathrm{Au}$ pad deposition and patterning.

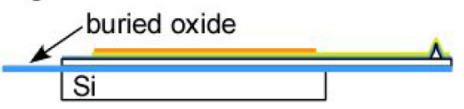

(5) Back side DRIE to form the cantilever structure.

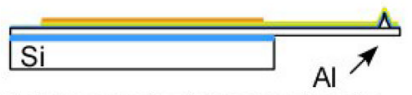

(6) Release probe by removing the buried oxide with BHF. Al deposition for reflection.

Fig. 1.

Process flow for fabricating the probe array. 

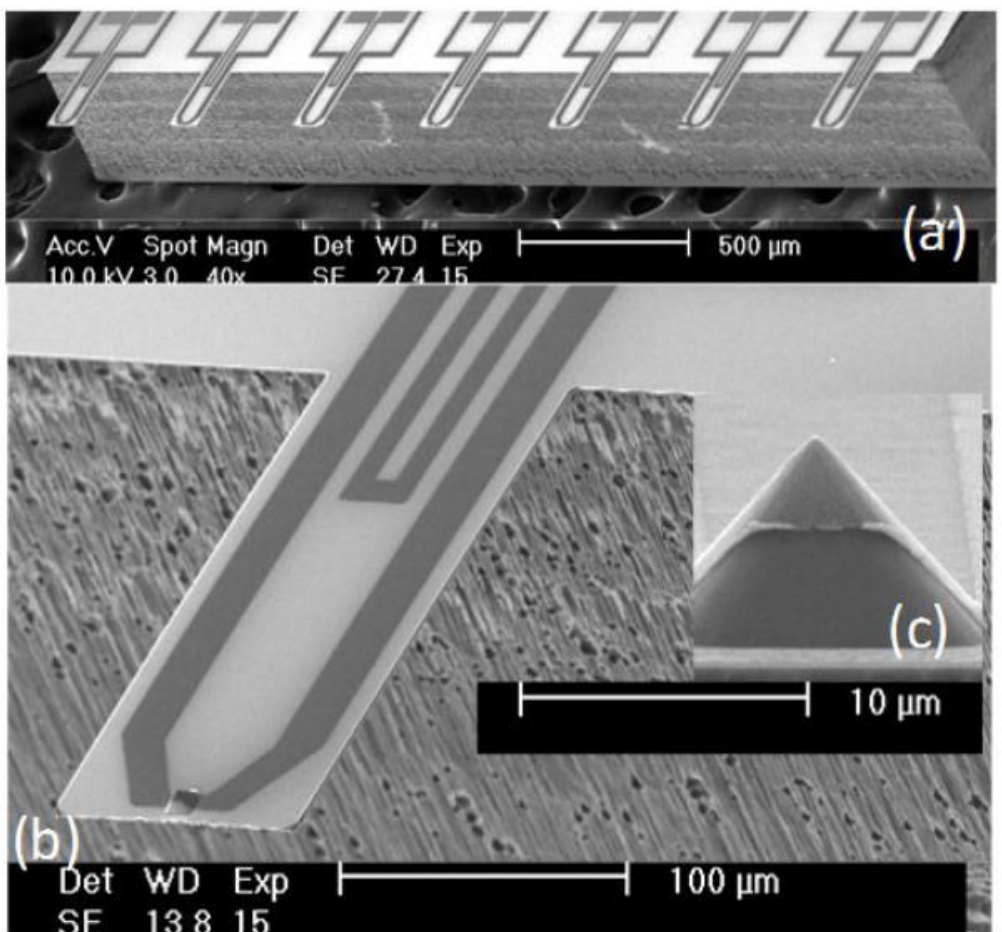

Fig. 2.

(a) SEM of the probe array. (b) Individual cantilevers include two resistors, one over the tip serving as a localized heater/thermal sensor and a second closer to the base serving as a resistor for deflection sensing. Inset (c) SEM close-up of the tip. 


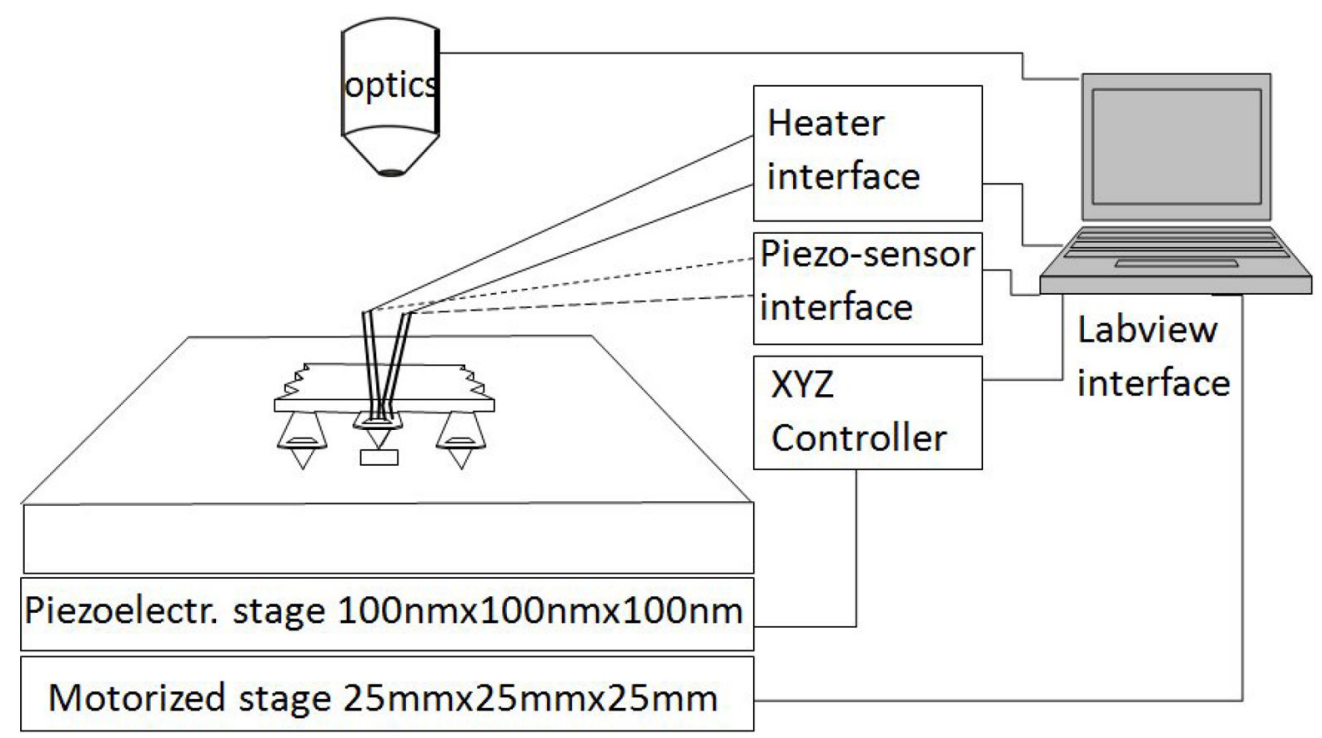

Fig. 3.

The experimental set-up used to conduct these studies. 


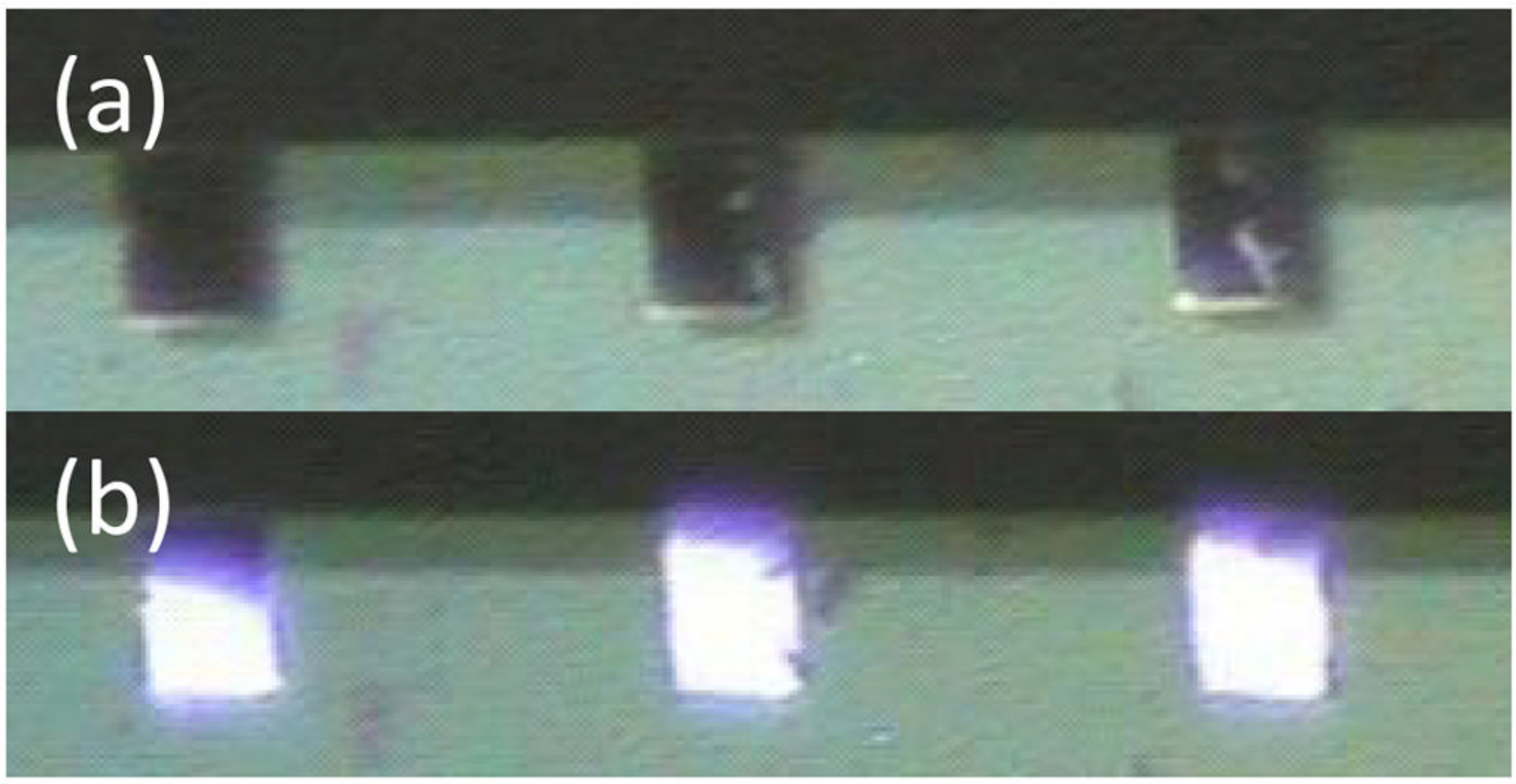

Fig. 4.

Probes are monitored using an optical microscope to determine contact, which occurs when the reflection changes. Here, three probes are shown (a) before contact and (b) after contact. 


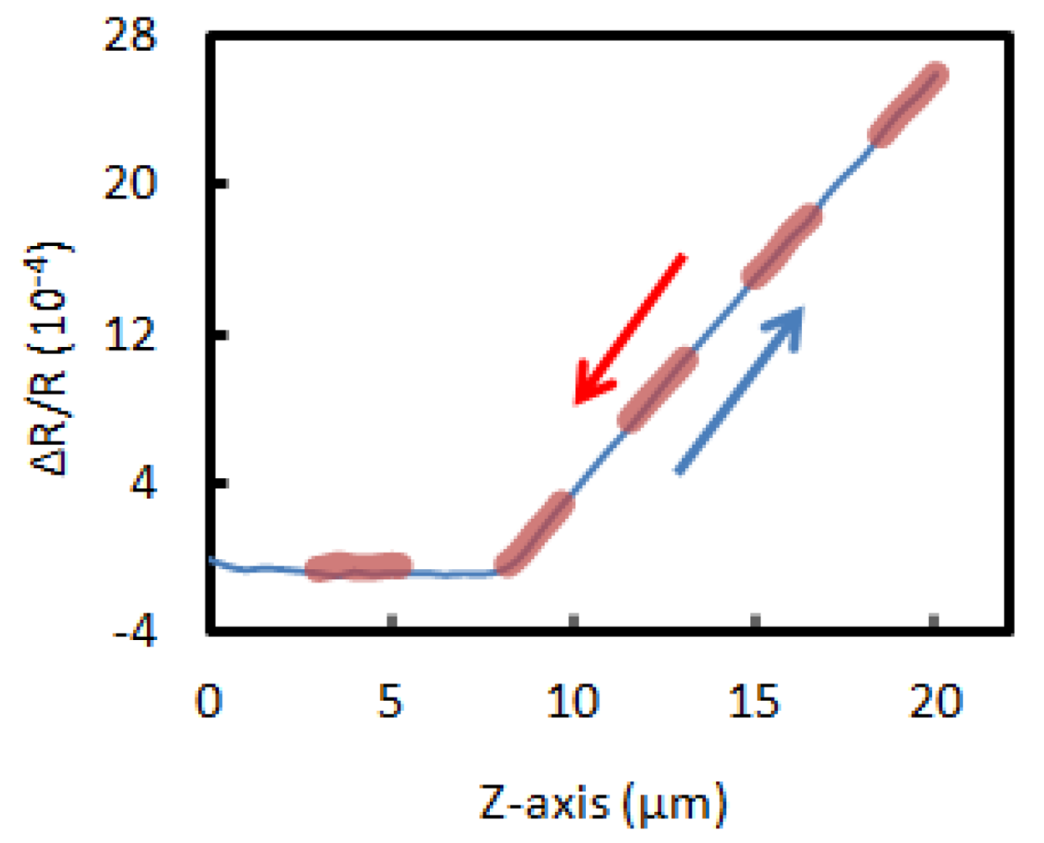

Fig. 5.

Electrical monitoring of probe-sample contact and cantilever characterization is done using "force-curves" of a probe on a hard substrate such as glass. 


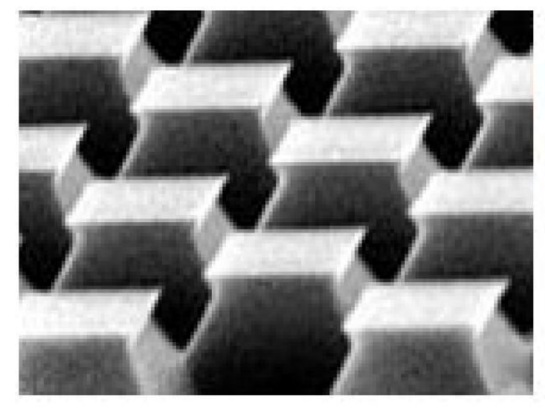

(a)

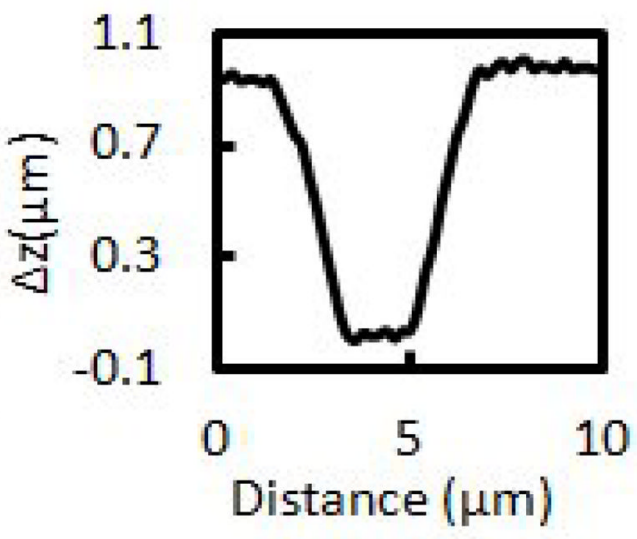

(b)

Fig. 6.

(a) SEM of $10 \mu \mathrm{m}$ pitch square grating with $1 \mu \mathrm{m}$ height. (b) A high resolution $10 \mu \mathrm{m}$ line scan. The probe moved in $0.2 \mu \mathrm{m}$ steps in the $\mathrm{X}$ direction. 

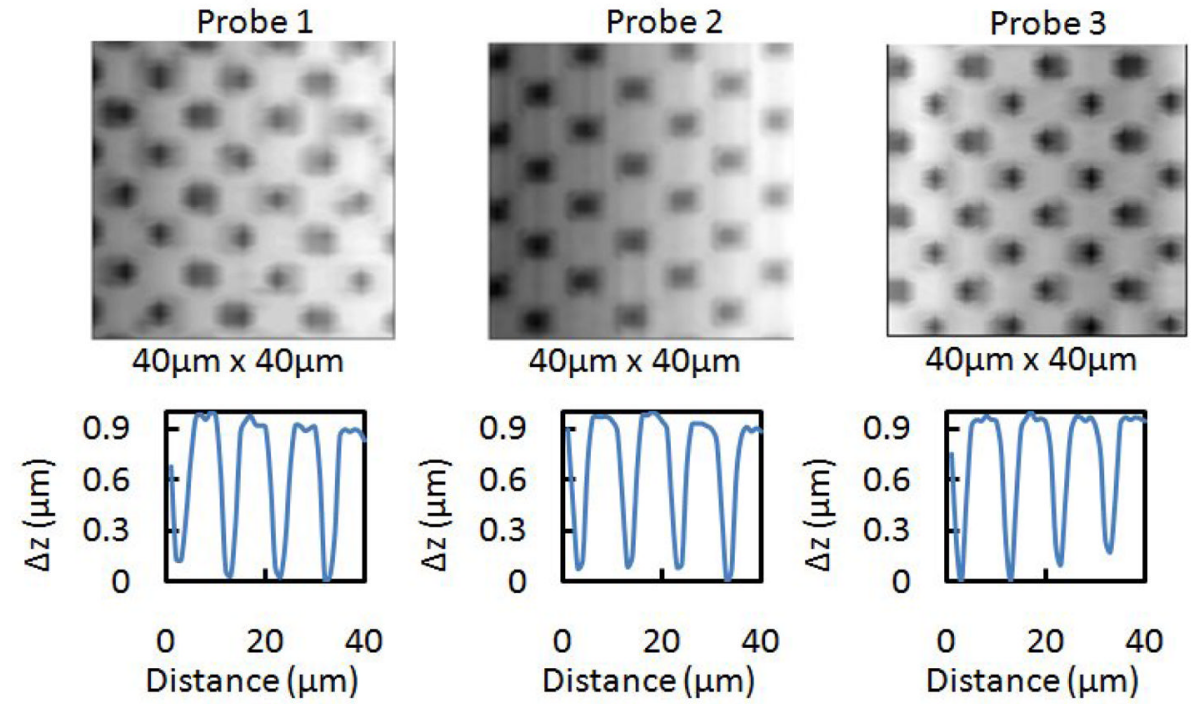

Fig 7.

A $40 \mu \mathrm{m} \times 40 \mu \mathrm{m}$ area scan acquired by 3 different probes scanned over the $10 \mu \mathrm{m}$ pitch square grating. 


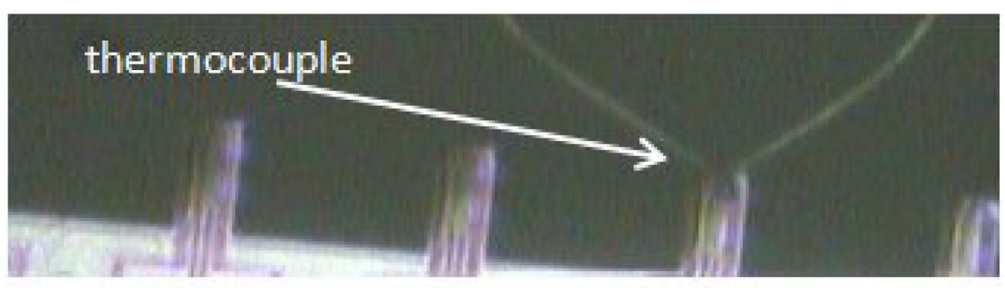

(a)

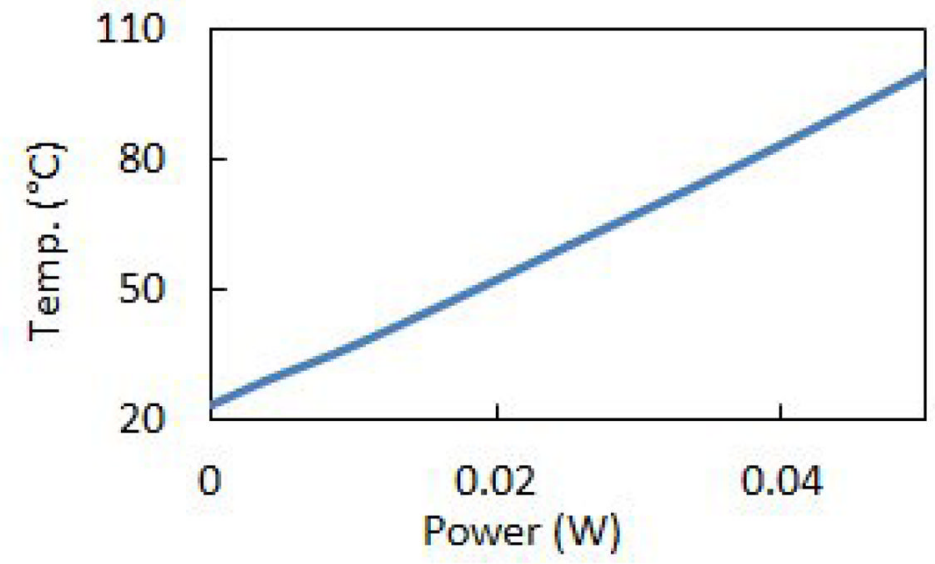

(b)

Fig. 8.

(a) An optical image of a $12 \mu \mathrm{m}$ thermocouple in contact with one of the probe tips of an array. The thermocouple is used to calibrate each heater. Each heater is heated gradually, while the current through the probe (I), the voltage (V) and the temperature at the tip are recorded. (b) The calibration curve of power vs. temperature from the measured data is very linear. From the resistance and temperature data the TCR is estimated to be approximately $655 \mathrm{ppm} / \mathrm{K}$. 


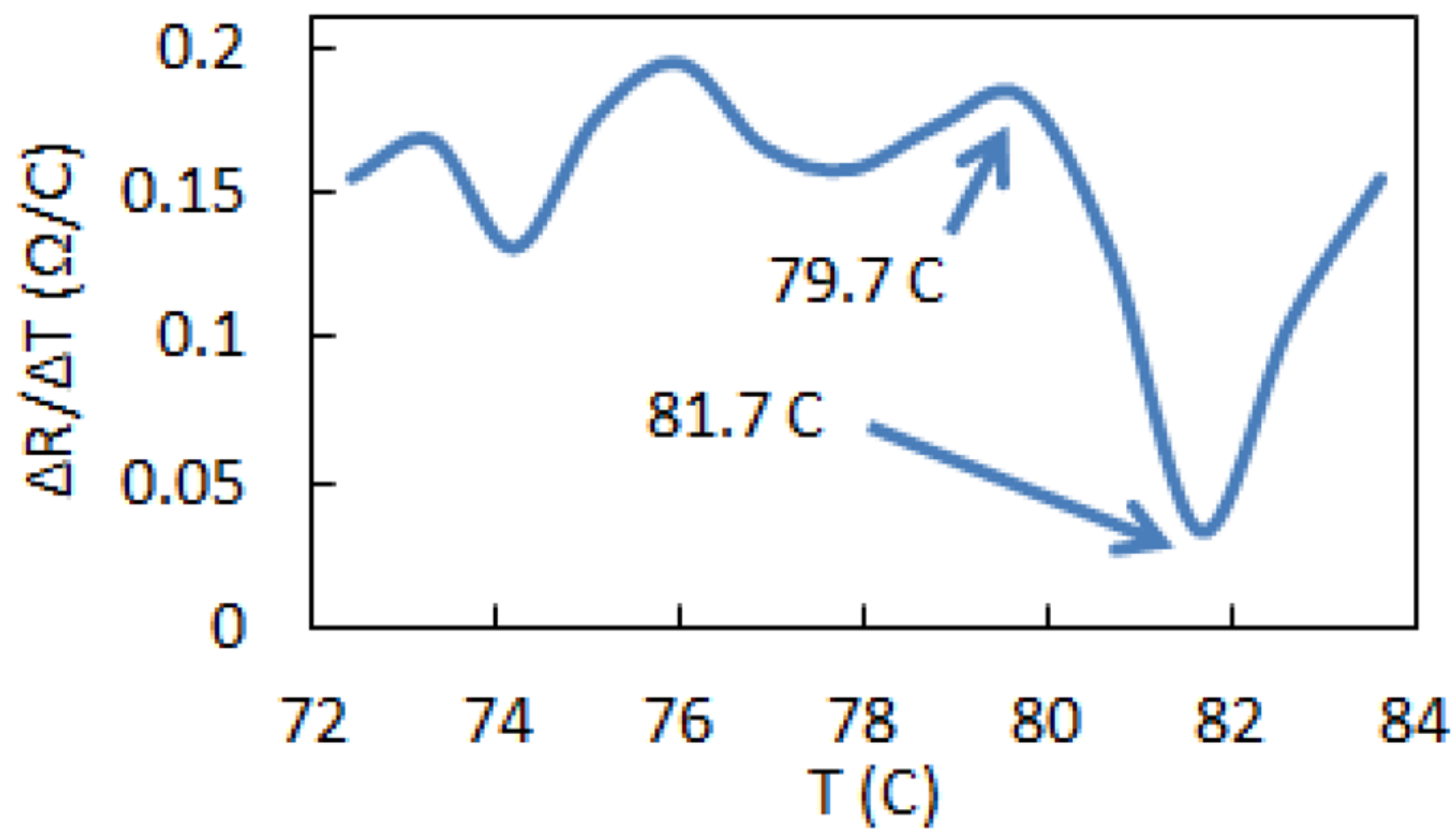

Fig. 9.

The first order derivative of change in resistance with respect to temperature vs. temperature is shown with knee point at $79.7 \mathrm{C}$. The $\mathrm{X}$-axis represents the temperature of the heater and the $\mathrm{Y}$-axis the change in resistance with temperature of the deflection sensing element. 